\title{
ERRATUM
}

\section{Trajectories of adolescent conduct problems in relation to cortical thickness development: a longitudinal MRI study}

S Oostermeijer, S Whittle, C Suo, NB Allen, JG Simmons, N Vijayakumar, PM van de Ven, LMC Jansen, M Yücel and A Popma

Translational Psychiatry (2016) 6, e899; doi:10.1038/tp.2016.134; published online 20 September 2016

Correction to: Translational Psychiatry (2016) 6, e841; doi:10.1038/ tp.2016.111; published online 21 June 2016
The versions of Figures 3 and 4 that appear in the paper are obsolete. The correct versions appear here. The publisher regrets this error. 

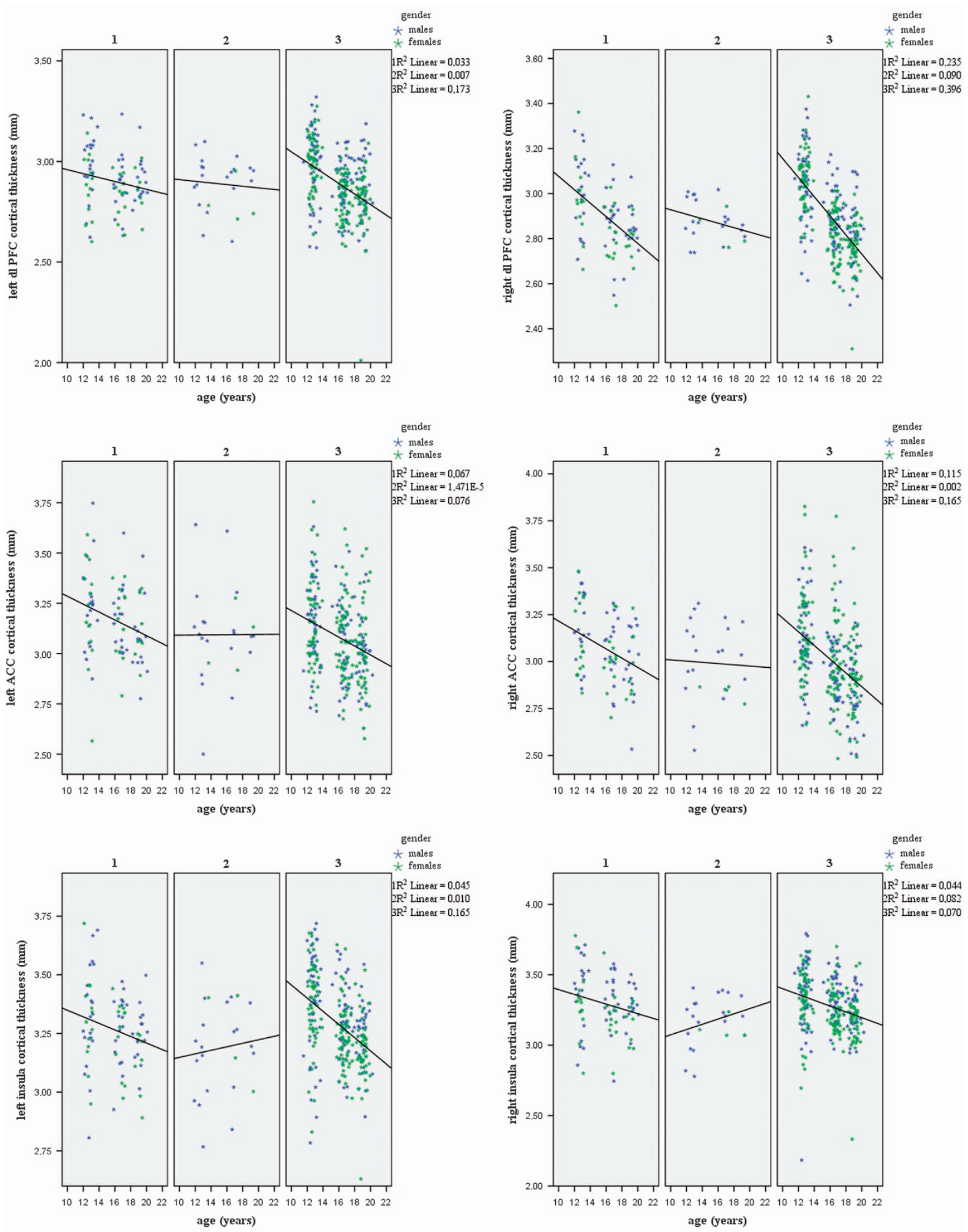

Figure 3. Uncorrected cortical thickness of the left and right dorsolateral prefrontal cortex (dl-PFC), anterior cingulate cortex (ACC) and insula with linear fitted lines. $1=$ the intermediate conduct problem group, $2=$ the desisting conduct problem group, $3=$ the stable low conduct problem group. 


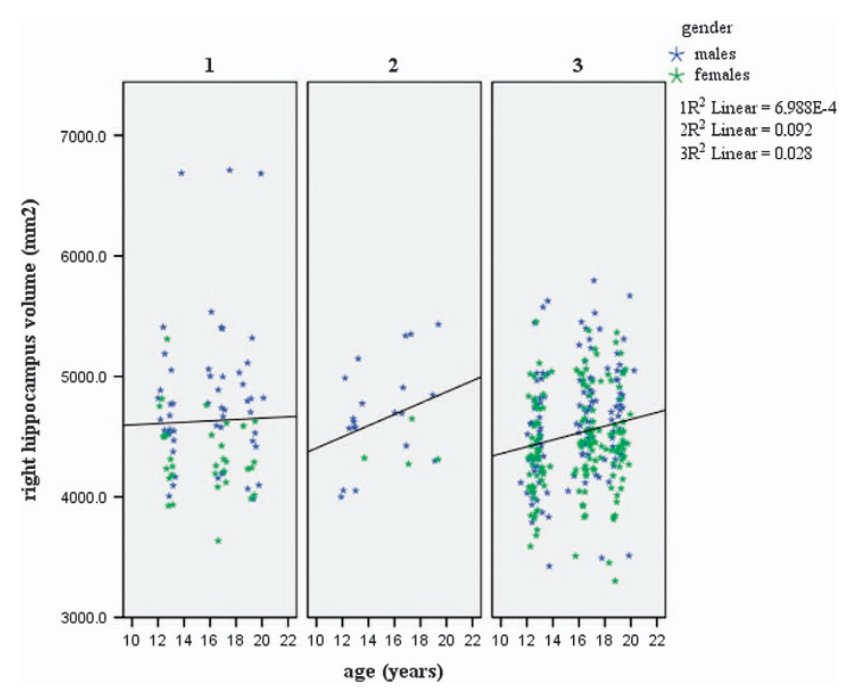

Figure 4. Uncorrected subcortical volume of the right hippocampus with linear fitted lines. $1=$ the intermediate conduct problem group, $2=$ the desisting conduct problem group, $3=$ the stable low conduct problem group. 